\title{
Escatología y marginalización en la literatura andina: las porosas fronteras sociopolíticas en Los ríos profundos de José María Arguedas
}

Este trabajo establece la existencia de una alegoría en Los ríos profundos (1958) de José María Arguedas, en la que los individuos marginados - los indígenas, los afroperuanos y las mujeres - se asocian con los materiales abyectos. Examino cómo esta alegoría critica la desigualdad económica y política del sistema sociopolítico peruano del siglo XX. Tal como el excremento fisiológico es esencial para que el sistema humano funcione, estos seres humanos, a pesar de su estatus marginado, son imprescindibles para el funcionamiento del Perú. Se demuestra que la frontera entre la hegemonía y los marginados no sólo es artificial, sino también vulnerable.

Palabras clave: José María Arguedas, literatura andina, Los ríos profundos, abyección, indigenismo, política

This paper establishes the existence of an extensive allegory in José María Arguedas's Los ríos profundos (1958), in which marginalized individuals Indigenous Peruvians, Afro-Peruvians, and women - are associated with abject materials. This allegory underscores and critiques the economic and political inequalities of mid-twentieth-century Peru's social system in order to demonstrate that, just as excrement is indispensable to the proper functioning of the human body, these individuals, despite their marginalized status, are essential to Peru's economy and body politic. Finally, I show how the border between the hegemony and the marginalized class is not only artificial, but also imminently vulnerable.

Keywords: José María Arguedas, Andean literature, Los ríos profundos, abjection, indigenismo, politics

Mierda. Excrementos. Excusados. Porquería. K'echas. Meones. K'anras: ${ }^{\mathrm{I}}$ los desechos humanos son ubicuos en Los ríos profundos (1958), novela semiautobiográfica del peruano José María Arguedas (I9II-69).² A lo largo de la narrativa, las referencias a la suciedad y el excremento se asocian con 
los seres más despreciados de la sociedad peruana a mediados del siglo XX. El presente estudio indaga el tema de la exclusión social y la falta de agencia política de grupos marginados en la narrativa - los indígenas, las mujeres y los afroperuanos - por medio de una interrogación de los elementos escatológicos, o todo "perteneciente o relativo a los excrementos y suciedades" ("Escatológico"), de la novela. Al igual que los excrementos humanos que se expelen del cuerpo biológico, los seres marginados del Perú se expulsan del interior social, mantenidos aparte por los individuos poderosos de la sociedad. El presente análisis tiene dos objetivos relacionados con la presencia de la escatología en la novela de Arguedas. Primero, se expone cómo Los ríos profundos exterioriza la configuración social de explotación y desigualdad en el Perú de mediados del siglo XX a través de un extenso alegorismo en que la escatología fisiológica funciona como una metáfora de la gente marginada. De forma relacionada, se señalan las maneras en que la asociación alegórica constituye un desencuentro epistemológico-ontológico, dado que el grupo dominante menosprecia lo escatológico, mientras que el grupo marginado reconoce su valor como material orgánico. Segundo, se revelan las maneras en que la exclusión sociopolítica que se funda en esta alegoría (escatología = marginado) no solo es artificial - se compone de una división sintética construida por la hegemonía - sino también es inminentemente vulnerable. Como se expondrá a continuación, la imposición y la vigilancia de esta frontera sintética resultan en su propia ruptura.

Los ríos profundos es narrada desde la perspectiva de Ernesto, un muchacho mestizo. El narrador lleva mucho de su juventud deambulando por el Perú con su padre, y exhibe una afinidad particular hacia los colonos (los trabajadores indígenas) de las haciendas por haber sido criado por mujeres indígenas. El último viaje con su padre los lleva primero al Cusco, 3 donde Ernesto conoce a su tío, don Manuel Jesús, apodado "el Viejo", y al sirviente-esclavo indígena de ese, el pongo. El Viejo es un odiado pariente que representa el mundo de los terratenientes prepotentes, hipócritas y abusivos. La experiencia en el Cusco plantea varios temas que estarán presentes a lo largo del texto: la penetrante estratificación social del Perú, el papel central de la Iglesia católica en la sociedad y la presencia de una cultura heterogénea en la vida cotidiana. Después de la visita al Cusco, Ernesto y su padre viajan a la ciudad de Abancay, donde el padre, antes de seguir el viaje, matricula a Ernesto en un colegio manejado por el Padre Linares. Los niños le apodan a Ernesto "el forastero", tanto por el hecho de que ha llegado desde afuera, como por el trato respetuoso que tiene con los indígenas y las mujeres. La simpatía que siente hacia las chicheras, las dueñas de los bares de chicha en el barrio Huanupata, es una muestra 
ejemplar de esta diferencia. Cuando ellas organizan un motín en contra del gobierno y los hacendados - robando sal de los ricos para distribuir a los colonos - Ernesto las sigue en apoyo, participando en la rebelión y defendiéndolas delante de sus amigos y el Padre Linares. Asimismo, Ernesto demuestra una bondad inaudita hacia los marginados colonos y cultiva una amistad con el único clérigo negro del colegio, el Hermano Miguel. La novela cierra con un brote de tifo, durante el cual los colonos se deshacen de su miedo de los oficiales, quienes han bloqueado el único puente con el fin de aislar a los colonos de la ciudad de Abancay. Los colonos entran a la ciudad por la fuerza para demandar la misa ante la posible muerte por la peste.

CONTEXTO ECONÓMICO, HISTÓRICO Y LITERARIO

Un elemento de la novela que ha tratado frecuentemente la crítica literaria es su naturaleza bilingüe y pluricultural. Llamada la primera novela neoindigenista por remitirse a menudo al lenguaje y la cultura quechua (Nagy 36), Los ríos profundos incorpora una plétora de expresiones y huaynos folclóricos en quechua. ${ }^{4}$ En su momento, la incorporación considerada de una lengua indígena en el género literario moderno por excelencia - la novela - constituyó una técnica narrativa sin precedentes. 5 Por lo general, la crítica coincide en que la novela posibilita la consideración de la coexistencia o la fusión de la cultura indígena y la cultura dominante. De este tema ha surgido un diálogo fructífero que cuestiona la manera más apropiada de interpretar la incorporación del indigenismo y el mestizaje en Los ríos profundos, un debate que todavía no se ha resuelto ni agotado. ${ }^{6}$ En cuanto a los elementos escatológicos, Los ríos profundos se sitúa dentro de una tradición literaria que emplea lo escatológico para llamar la atención a la situación de los grupos marginados de la sociedad. La abyección es empleada como recurso literario en otras novelas de la época, tanto de Arguedas como de otros autores andinos. Escritores contemporáneos de Arguedas, tales como Alcides Arguedas (I879-1946, Bolivia), Jorge Icaza (1906-78, Ecuador), Ciro Alegría (1909-67, Perú) y Manuel Scorza (1928-83, Perú), incorporan elementos escatológicos en sus obras a fin de exponer lo injusto de la realidad indígena y de reivindicar los derechos de la gente indígena. 7

Teniendo en cuenta la historia económica del Perú, no es de extrañar que lo escatológico se emplee como metáfora de la disparidad social y económica de la época. La economía peruana fue transformada de manera radical durante la llamada Era del Guano, que duró de i84I, cuando empezó el comercio de exportación del guano, hasta aproximadamente i878, año anterior al estallido de la Guerra del Pacífico con Chile (Reinhalter Burner I). Durante esa época, el Perú se convirtió en una economía mercantil- 
liberal, como observa José Carlos Mariátegui: "Las utilidades del guano y del salitre crearon en el Perú, donde la propiedad había conservado hasta entonces un carácter aristocrático y feudal, los primeros elementos sólidos del capital comercial y bancario" (I7). El guano - producto excremental extraído de las islas del litoral peruano - proviene etimológicamente de wanu, un término del quechua (Soto Ruiz 15). A pesar de su papel fundamental en la economía, el guano se aisló geográfica y hasta lingüísticamente de la hegemonía peruana. De tal modo, es lógico que el guano se emplee como metáfora de los grupos que son, a la vez, socialmente excluidos y económicamente imprescindibles.

Desde su primer libro, Yawar fiesta (Fiesta de sangre 194I), cuyo título evoca un material abyecto, hasta la novela póstuma, El zorro de arriba y el zorro de abajo (1971), ${ }^{8}$ la abyección tiene un papel central en la obra de Arguedas. En "El sueño del pongo (cuento quechua)", lo escatológico no es solo una metáfora, sino el material mismo de la venganza narrativa. En este cuento, un pongo, nombre que designa un sirviente indígena de casa, sufre en silencio frente a la humillación y el abuso de su patrón. En frente de los otros sirvientes de casa, el patrón cuestiona su humanidad, lo cachetea y hace que imite a animales. Sergio R. Franco postula que la indecisión del amo con respecto a la humanidad del pongo y su constante abuso son resultado del estado abyecto del sirviente. Refiriéndose a la teoría de Kristeva, Franco explica que lo abyecto "se produce cuando colapsa el sentido y aflora todo aquello que no respeta posiciones ni reglas ... Lo abyecto nos fascina, provoca nuestro goce, pero, a la vez, nos atemoriza y repele, porque amenaza las fronteras (imaginarias) de nuestro ser y nuestro universo, confundiendo sus límites" (325). Parecido a lo que se verá en Los ríos profundos, el amo de "El sueño del pongo" maltrata a su sirviente a fin de fortalecer el límite inventado entre su propio ser y ese ser abyecto que amenaza al orden patriarcal-feudal.

Sin embargo, después de sufrir los abusos de su amo por mucho tiempo, el epónimo pongo se dirige al patrón en quechua frente a toda la gente de la hacienda. Le relata un sueño suyo en que los dos hombres llegan al cielo y, desnudos, esperan que San Francisco los juzgue. La narración del sueño parece reafirmar la estructura del poder de la tierra, dado que San Francisco manda que los ángeles cubran al patrón con miel y al pongo con excremento humano. No obstante, el desenlace del sueño subvierte las expectativas, cuando San Francisco decreta que el pongo y el amo se laman "por mucho tiempo" como juicio final (Arguedas, "Sueño" 237). En vez de (solo) servir una función metafórica, en "El sueño del pongo", los excrementos humanos se emplean como vindicación celestial por los pecados del patrón abusivo. 9 
De manera similar, El Sexto (I96I), la novela más explícitamente escatológica de Arguedas, remite a lo escatológico para simbolizar la degradación moral y física de los encarcelados. Narrada por Gabriel desde la epónima prisión limeña, El Sexto ha sido descrita como un nuevo infierno dantesco (Sandoval 153) que sirve como testimonio novelesco de los ocho meses que Arguedas pasó en la cárcel en 1937-38 por protesta política. Los episodios en que sobresale lo abyecto - ingestión de excremento, hombres hambrientos lamiendo sangre del piso, violación anal en grupo, orinas, suciedad, vómito, cadáveres - son numerosos y grotescamente explícitos, por lo que Ignacio López-Calvo concluye: "In the novel, Arguedas shows a neo-naturalist fascination for that which is filthy and oppressive in society. ... all these degrading scenes inextricably link human physiology to sociopolitical and cultural conflicts" (I44). A diferencia de la novela posterior, Los ríos profundos, lo escatológico en El Sexto es vil y negativo un cambio de perspectiva que demuestra una evolución en la epistemología narrativa del autor.

La historia económica del Perú junto a la presencia persistente de lo escatológico en la obra literaria de Arguedas indica que la abyección es un marco productivo para analizar Los ríos profundos. Y aunque la crítica ha examinado lo escatológico en otras obras de Arguedas, son escasos los estudios que lo tratan en Los ríos profundos. Entre los pocos estudios existentes, Amy Fass Emery asocia la suciedad de los indígenas y las mujeres con lo grotesco y la repulsión, enfatizando la manera en que los espacios indígenas se relacionan con "the trauma of sexuality" (60). Asimismo, Priscilla Archibald observa que lo sucio se entremezcla con la sexualidad traumática y grotesca para llevar a cabo una deconstrucción narrativa de las relaciones coloniales, ejemplificando así cómo funciona la ideología colonial-colonizada (132). El presente análisis concurre con esta crítica hasta cierto punto: la novela hace explícita la perspectiva de la Iglesia católica, los terratenientes y los políticos, cuya epistemología suele menospreciar todo lo abyecto como material sucio e inmundo. Sin embargo, también pretendo ir más allá de este binarismo hegemónico, y planteo que Los ríos profundos rescata lo abyecto por su valor como material orgánico imprescindible para la vida.

Coincidiendo con el presente análisis, Karen Spira propone que Los ríos profundos postula una relación afectiva con lo escatológico, y destaca las maneras en que Ernesto aprecia materiales que generalmente se consideran inmundos. Spira propone que Ernesto goza de una "indigenous perspective" que permite una sensibilidad ecológica, "according to which all elements of material reality - not just the rose in full bloom, but also the dirt that nurtures its growth and the insect and bacterial life that aid in its 
decomposition - carry meaning and value" (74). Spira observa que Los ríos profundos propicia una estética de lo abyecto, subrayando un modo de percibir que saca placer de la potencia de lo sucio. Según Spira, esta perspectiva es incomprensible para la clase dominante. De acuerdo con Spira, el presente trabajo destaca cómo la narrativa comprende dos puntos de vista contrarios a través del mestizaje de Ernesto, manifestando así las percepciones del joven mestizo como aliado de los marginados, pero también como hombre blanco aceptado por la clase dominante.

Debido a la fluidez con que Ernesto se maneja en el mundo mestizo, el lector se percata de la ideología de la cultura dominante, que mantiene oprimidos a los indígenas, a las mujeres y a los afroperuanos al asociarlos con la suciedad. A través de la simpatía de Ernesto por los indígenas, el lector también se entera del valor de una relación simbiótica con los materiales escatológicos. La yuxtaposición de estas dos perspectivas expone un desencuentro fundamental entre la epistemología sociopolítica de la clase dominante en el Perú y la ontología de la gente indígena. Propongo el término "desencuentro" para conceptualizar esta discrepancia, porque desvela cómo dos grupos pueden tanto relacionarse con el mismo material como opinar sobre él de maneras totalmente distintas. En la teoría latinoamericana, "desencuentro" ha sido utilizado para concebir cómo dos aliados fracasan en movimientos revolucionarios debido a la falta de entendimiento mutuo sobre las estrategias y el porqué de la revolución compartida. ${ }^{\circ}$ Jeffrey Gould propone que un desencuentro surge dado que "two different groups can have different understandings of the same concept that, in turn, may condition different practices in a given historical moment" (287).

En la novela de Arguedas, el desencuentro existe debido a que la clase dominante en el Perú dispone del sistema ontológico de los marginados un sistema que valora lo escatológico como una parte vital de la existencia - para construir su propio sistema epistemológico. Este desencuentro epistemológico-ontológico evidencia la naturaleza arbitraria y contingente de la división sociopolítica. Los que definen y defienden el interior hegemónico son irremediablemente vulnerables a la misma cualidad que utilizan para demarcar el límite entre los incluidos y los excluidos dado el simple hecho de que, como seres humanos con cuerpos biológicos, ellos también tienen que defecar, sudar y orinar para sobrevivir. Ellos producen y entran en contacto con los mismos elementos "sucios" que emplean para excluir a los marginados de la sociedad peruana. El siguiente análisis elucida las maneras en que los sujetos hegemónicos - los hacendados, los clérigos y los militares - recurren a lo escatológico para separarse de los sujetos 
oprimidos - los indígenas, las mujeres y los afroperuanos - y medita sobre la permeabilidad y vulnerabilidad de la frontera que separa a los dos grupos.

LA ESCATOLOGÍA Y LA ABYECCIÓN COMO FRONTERA SOCIOPOLÍTICA

En Gender Trouble, Judith Butler propone leer el cuerpo humano como una sinécdoque para el sistema social y establece cómo los contornos corporales aprobados son inscritos por las normas culturales (I68-69). Como ejemplo, Butler describe las maneras en que muchas culturas actuales juzgan el coito homosexual y, en particular, la penetración anal u oral entre hombres, una transgresión inmoral y una polución del cuerpo humano. Para estas culturas, el ano constituye una frontera corporal que no se puede cruzar y cualquier penetración de éste se categoriza como "unregulated permeability" (I69). Asimismo, a través de referencia a Julia Kristeva, Butler plantea que los individuos abyectos de una comunidad se expulsan, como excremento, del cuerpo social con el fin de mantener una frontera discreta entre lo aceptable y lo excluido (I69-70). ${ }^{-1}$ El concepto de la permeabilidad no regulada es clave para el presente trabajo. Como se verá, la clase dominante de terratenientes, clérigos y militares (todos hombres blancos) en Los ríos profundos busca vigilar y controlar una frontera discreta entre ellos mismos y los indígenas, los negros y las mujeres rebeldes o locas. El símbolo principal que representa esta frontera es lo escatológico que consiste en las secreciones humanas (lágrimas, orines, excrementos, sudor) y la suciedad. Pero dada la artificialidad de la frontera, esta resulta vulnerable. Esta vulnerabilidad toma la forma de la permeabilidad no regulada. En varias ocasiones en la trama, la penetración no regulada ocurre y la clase dominante busca fortalecer la frontera discreta a través de la reproducción de la separación basada en lo escatológico. Como demostraré, se vuelve más y más difícil mantener la frontera discreta entre el interior aceptado y el exterior abyecto, una dificultad que surge del papel integral que los marginados juegan en el sistema socioeconómico de la época.

A lo largo de Los ríos profundos existe una dicotomía explícita entre las figuras de la clase dominante y los grupos reprimidos que se relaciona con la limpieza del cuerpo físico. La diferencia entre la clase dominante y la dominada sobresale al contrastar el Viejo con el pongo del primer capítulo. El Viejo, hombre rico que lleva bastón con punto de oro, ${ }^{12}$ es dueño de una casa en el Cusco y una hacienda grande en las afueras de la ciudad. Tiene sirvientes y tanto dinero que deja pudrir las frutas de sus huertas porque valen "muy poco para traerlas a vender al Cuzco" (Arguedas, Ríos profundos I38). Es ostensiblemente un católico devoto y, a pesar de ser una persona desagradable, gana el respeto de todos en el Cusco. Destaca por contraste el estado deteriorado del pongo, el desnutrido y maltratado sirviente (más 
bien esclavo) del Viejo que, al conocer a Ernesto y su padre por primera vez, se inclina ante ellos "como un gusano que pidiera ser aplastado" (157). Con ropa desgastada, los pelos "revueltos, cubiertos de inmundicia" (I63), el pongo le da lástima a Ernesto por ser el hombre más humillado que jamás haya visto. Tanto el estado físico sucio del pongo como su conducta sumisa reflejan su posición social, o la falta de alguna posición, frente la riqueza del Viejo. Como enfatiza Fass Emery, "the scatological plays a role in class warfare in Deep Rivers because the Imaginary of the controlling elite has constructed an image of the oppressed Indian population as filthy, reeking, and diseased" (6r). De tal manera se inicia una alegoría que persiste a lo largo de la novela.

La suciedad de las viviendas de los grupos marginados también sirve para justificar la separación física de los dos grupos. Cuando Ernesto va a la hacienda Patibamba con el motín de las chicheras, por ejemplo, nota que "la gran residencia" del dueño se separa de la ranchería de los colonos por rejas y columnas guarnecidas por mestizos con fusiles. Enfrente de la casa un hombre vestido de blanco está de pie observando el motín. Al llegar a la ranchería, Ernesto encuentra la antítesis de la ordenada grandeza de la hacienda. Las chozas, infestadas por avispas, se hallan en calles cubiertas "de la melaza y de los excrementos humanos" (Arguedas, Ríos profundos 283) y las indígenas se comportan de manera antitética a la del hacendado vestido de blanco. Mientras que este, parado entre sus dos guardianes armados, se muestra indiferente ante la bulla de las chicheras, las indígenas se esconden en sus casas. Solo después de que las chicheras las animan, salen brevemente "entre un murmullo ininteligible" para recibir la sal robada y pronto vuelven a sus casas (282). La yuxtaposición de la gran residencia y las chozas exhibe por excelencia el contraste entre lo limpio y ordenado de los apoderados frente lo escatológico de los marginados. Butler explica que este tipo de separación vigilada entre dos grupos es una manera calculada de excluir a los marginados de la sociedad: "In effect, this is the mode by which Others become shit" (170). Además, esta escena demuestra una distinción relacionada, aquella entre los dominantes, los que están seguros de su lugar en el sistema social, político y económico, y los dominados, los cuales carecen de voz política.

Además del aspecto físico, la percibida falta de voz política resalta la falta de estatus político de los últimos. Poco después de llegar a Abancay, Ernesto se topa con unos indígenas e intenta hablarles en quechua. Ellos se niegan a dialogar con el mestizo, respondiendo con “iMánan!” (Arguedas, Ríos profundos 200), 13 la misma negación que le da el pongo en el Cusco. Según Julio Ortega, en ciertos contextos, manan es una forma de negación que señala que "[el pongo] carece de un papel en la comunicación, que lo 
distinguiría como un ser específico: su papel de siervo lo excluye del habla misma, que lo aterra. $Y$ aun cuando responde da como su origen, en verdad, su pertenencia, a un sistema económico, la hacienda, base de su papel dominado" (52).I4 Asociando el lenguaje con el aspecto físico de los colonos en Abancay, Ernesto nota que ellos tienen "la misma apariencia que el pongo del Viejo. Un sudor negro chorreaba de sus cabezas a sus cuellos; pero eran aún más sucios, apenas levantados sobre el suelo polvoriento del caserío y de la fábrica, entre las nubes de mosquitos y avispas" (Arguedas, Ríos profundos 200). Al no recibir ninguna respuesta a pesar de sus insistentes interpelaciones, concluye que los colonos "ya no escuchaban ni el lenguaje de los ayllus [comunidad de los indígenas]; les habían hecho perder la memoria; porque yo les hablé con las palabras y el tono de los comuneros, y me desconocieron" (200). Hay dos maneras de interpretar las observaciones de Ernesto. Si tiene razón y el manan de los indígenas es igual a la auto negación del pongo, se demuestra lo eficaz que ha sido la marginalización dado que ellos no se consideran parte del cuerpo político. Sin embargo, si Ernesto se equivoca y, en vez de negarse a sí mismos, los colonos se niegan a hablarle a él, se demuestra la potencia de la epistemología hegemónica, dado que el autoproclamado aliado de los indígenas mal interpreta el manan como renuncia, cuando, en verdad, constituye agencia sociolingüística. ${ }^{15}$

El significado sociolingüístico tras la renuncia señalada por el manan del pongo (y la percibida renuncia de los colonos de Abancay) se profundiza al considerarlo al lado de la teoría de la política de Jacques Rancière. Rancière propone que la sociedad se estructura por los que cuentan y los que no cuentan. Los primeros forman parte del llamado "reparto de lo sensible", o sea, todos los individuos que disfrutan de una presencia política en común en la sociedad (6). Los que cuentan se hacen oídos, vistos, perceptibles. En contraste, los que no cuentan son las personas que no forman parte de la sociedad política porque no se perciben políticamente. No disfrutan de la misma agencia política de los que cuentan. Refiriéndose a la dicotomía entre voz y habla propuesta por Aristóteles, ${ }^{16}$ Rancière explica que los que cuentan forman parte del reparto de lo sensible, dado que "[t]he supremely political destiny of man is attested by a sign: the possession of the logos, that is, of speech, which expresses, while the voice simply indicates" (2). Entendido al lado de esta conceptualización del reparto de lo sensible, el manan del pongo conlleva un significado profundo; el lenguaje mismo niega su posición en la sociedad dominante.

Para la hegemonía, el estado físico de los marginados corresponde a su falta de identidad política; la suciedad refleja y refuerza el bajo valor que la sociedad les otorga. Como se ha visto en la descripción de las chozas, el 
entorno social de los marginados y los lugares asociados con ellos también se saturan de una suciedad que resalta su exclusión social. El caso de la Opa Marcelina, ${ }^{17}$ una de las figuras más explotadas de la narrativa, es llamativo. Descrita como demente blanca con rostro inmundo, sirve de ayudante en la cocina del Colegio de Abancay. Los chicos del Colegio y el Padre Augusto la violan con frecuencia, y los estudiantes se pelean violentamente para ganar la oportunidad de violarla. Cuando ella intenta escaparse de ellos, "casi siempre alguno la alcanzaba todavía en el camino y pretendía derribarla" (Arguedas, Ríos profundos 217). Además de la violencia extrema que acompaña estos actos sexuales, es llamativo que la violación tome lugar al lado y dentro de los excusados. Ernesto describe las letrinas como "un espacio endemoniado" cuya "fetidez nos oprimía, se filtraba en nuestro sueño ... Algunos, unos pocos de nosotros, iban, siguiendo a los más grandes. Y volvían avergonzados, como bañados en agua contaminada" (227). La Opa Marcelina, cuyo género y estado mental prohíben que ella forme parte del reparto de lo sensible, se asocia con el fétido lugar de los excusados. Es más, el lugar de los expulsados se convierte en un espacio de tortura para los estudiantes, un sitio a la vez odiado y anhelado por el acto sexual que simultáneamente les atrae y les repugna. Ellos se convierten en bestias por sus ganas de violar a la demente, pero terminan avergonzados y arrepentidos.

Fass Emery establece que, a pesar de que Marcelina es una mujer blanca con pelo rubio y ojos azules, su estado mental y la suciedad de su cuerpo efectivamente la convierten en india (63). Como alegoría, la violación de la Opa representa la violación de las normas sociales del Perú. Al acostarse con la Opa, el Padre Augusto y los chicos del Colegio transgreden los s aprobados de la sociedad, originando la permeabilidad no regulada entre la mujer marginada y los hombres que forman parte de los que cuentan. La ambivalencia psíquica que resulta de estos encuentros con la Opa subraya la escisión traumática que divide la sociedad. En "Remembering, Repeating and Working-Through" (19I4), Sigmund Freud elabora la manera en que un sujeto posee memorias obtenidas durante la niñez que no recuerda, memorias reprimidas que nunca se pueden recuperar en la memoria activa. Sin embargo, a pesar de no recordar una memoria, el sujeto la repite, "reproduc[ing] it not as a memory but as an action; he repeats it, without, of course, knowing that he is repeating it" (Freud 150). Las acciones ambivalentes de los estudiantes, primero buscando contacto sexual con la Opa Marcelina y luego arrepintiéndose de la doble violación - la violación de la Opa y la de las normas sociales que establecen la prohibición de este contacto - concuerdan con las observaciones de Freud. Los estudiantes son incapaces de evitar el lugar de los expulsados y sueñan con volver al lugar, 
pero una vez que han violado a la Opa, repiten la represión original, o sea, se separan de la Opa, sienten vergüenza, rezan por absolución y se prometen que jamás volverán a visitar las letrinas. Este ciclo interminable de violación y restauración de la represión original subraya el trauma social ocasionado en el inconsciente de la sociedad peruana por la frontera arbitraria entre la hegemonía y los marginados.

Es más, la relación conflictiva con la Opa Marcelina, una figura abyecta, revela lo que Kristeva llama "the objective frailty of symbolic order" (70). Esta fragilidad del sistema político expone la permeabilidad social tan temida por la clase dominante. Mientras las rejas trazan una frontera discreta entre las chozas y la gran residencia de la hacienda, la proximidad sin barrera de la Opa Marcelina permite el contacto - y contacto explícitamente prohibido - entre los del interior y un miembro de los expulsados. De acuerdo con Kristeva, Butler observa, "if the body is synecdochal for the social system per se or a site in which open systems converge, then any kind of unregulated permeability constitutes a site of pollution and endangerment" (I68). No hay mejor lugar que los excusados para simbolizar el contacto con la Opa. Las reacciones de los estudiantes tras el contacto sexual con la inmunda demente revelan su horror al exponerse a lo abyecto, un contacto que Kristeva llama "defilement" (58), o profanación. La profanación ocurre en el momento en que falla la permeabilidad regulada, o sea, cuando la inmundicia de un ser abyecto "contamina" al sistema social.

La exclusión de los seres despreciados siempre será imperfecta dado que los expulsados son arrojados hacia afuera del sistema, o sea, forman parte del mismo sistema social: "filth is not a quality in itself, but it applies only to what relates to a boundary and, more particularly, represents the object jettisoned out of that boundary, its other side, a margin" (Kristeva 69). Lo importante de esta dinámica es que lo interior se define por un exterior artificial. Hay un margen debido a la existencia de los expulsados, así que los del interior fundamentan su identidad en la diferencia irónicamente definida y delineada por ellos mismos - entre ellos y los del exterior, simbolizados por lo abyecto, los excrementos humanos. De ahí se entiende que la permeabilidad regulada siempre está en peligro, porque la frontera no es natural, sino construida sintéticamente con base en los expulsados que son, paradójicamente, necesarios para el funcionamiento del sistema.

VIGILAR Y CONTROLAR LA FRONTERA POROSA

Los hombres poderosos que forman parte de los que cuentan en la teoría de Rancière son los que exhiben el mayor recelo hacia la permeabilidad no 
regulada. El Viejo, el Padre Linares y el Coronel, un militar que viene del Cusco para sofocar el motín de las chicheras, vigilan y pretenden mantener la frontera discreta entre el "reparto" de lo sensible hegemónico y los marginados que "no cuentan". Rancière nombra esta acción de vigilar y reproducir el reparto de lo sensible "policing" (28-29), o controlar. Las maneras en que pretenden controlar el reparto de lo sensible difieren según cada individuo de la hegemonía. El Viejo representa la clase terrateniente de los ricos hacendados cuya identidad hegemónica y capacidad económica dependen de los colonos. Como se ve en el trato del pongo, el Viejo necesita a los colonos para mantener sus haciendas productivas y rentables, pero no los trata como seres humanos. Su estrategia de subyugación es una de dominación y represión y el estado patético del pongo pone en evidencia la eficacia de sus métodos.

Mientras el Viejo priva de comida a los colonos y los maltrata como si fueran animales despreciables, el Padre Linares les infunde con la Palabra de Dios para que obedezcan y sean sumisos. Este siente un placer sádico al hacer llorar a sus oyentes indígenas. El día después del motín, por ejemplo, cuando los reprende por la sal robada, el Padre concibe un sermón con el propósito de desesperar a los indígenas: “¡Aquí hemos venido a llorar, a padecer, a sufrir, a que las espinas nos atraviesen el corazón como a nuestra señora! ¿Quién padeció más que ella? ¿Tú, acaso, peón de Patibamba, de corazón hermoso como el del ave que canta sobre el pisonay? ¿Tú padeces más? ¿Tú lloras más ... ?" (Arguedas, Ríos profundos 300). Sigue gritándoles, diciéndoles que "el mundo es una cuna de llanto para las pobrecitas criaturas, los indios de Patibamba" (300). El deseo de hacer llorar representa otra manera de excluir a los despreciados del cuerpo político. Aunque las lágrimas no suelen asociarse con lo abyecto porque no repulsan como otras secreciones humanas (Kristeva $7 \mathrm{I}$ ), siguen siendo un material expulsado del cuerpo físico. Por consiguiente, figuran el lado exterior de la frontera alegórica entre los marginados y los dominantes de una manera diferente. Alain Badiou propone que hacer sufrir reduce al hombre al "status of a victim, of suffering beast, of emaciated, dying body, [equating] man with his animal substructure" (II). Rancière destaca cómo este deseo de reducir a los marginados a mera bestia es parte fundadora del reparto de lo sensible (22). Como si fueran el animal de Aristóteles que emite ruido sólo para expresar dolor o placer, el Padre Linares busca que los indígenas lloren sin poder expresar la injusticia de no tener acceso a la sal.

El tema del sufrimiento surge una y otra vez en Los ríos profundos, haciendo patente el papel central que la victimización y el sufrimiento tienen en el mantenimiento del orden sociopolítico. La Iglesia católica en particular se asocia con la provocación del sufrimiento en la novela. En el 
Cusco, la presencia de la doliente estatua de Cristo, la sombra ominosa de la Catedral y los tristes golpes de la María Angola (la campana de la Catedral) hacen que Ernesto conjeture que "en ningún sitio debía sufrir más la criatura humana" (Arguedas, Ríos profundos i68). El Padre Linares tiene un papel similar en Abancay. Notablemente, Ernesto se percata de que sus sermones varían considerablemente según a quien se dirige:

El Padre hablaba esta vez de otro modo, no como lo hizo en el tabladillo de la hacienda, frente al patio barroso que pisaban los colonos de Patibamba. Quizá era una idea, un presentimiento sólo mío. El quechua en que habló a los indios me causaba amargura. “¿Tiene varios espíritus?”, me pregunté, oyéndole en la capilla. “A nosotros [los chicos del Colegio] no pretende hacernos llorar a torrentes, no quiere que nuestro corazón se humille, que caiga en el barro del piso, donde los gusanos del bagazo se arrastran ... A nosotros nos ilumina, nos levanta hasta confundirnos con su alma ...". (313)

Aquí se resaltan las tácticas que emplea el Padre Director para controlar la frontera entre los que forman parte del interior y los expulsados. Cuando evangeliza a los colonos, el tono y contenido del sermón les infunden con miedo y amargura, así asegurándose de que sigan siendo fáciles de manipular. En cambio, los chicos del Colegio se sienten fortalecidos e iluminados tras el sermón.

EXCEDERSE Y DISPUTAR FRONTERAS

Hasta ahora el presente análisis se ha enfocado en grupos marginados que no han desafiado su papel de expulsado pero Los ríos profundos complica la dinámica interior-exterior a través de varios grupos marginados que cuestionan su posición social. El caso de las mujeres chicheras exhibe el riesgo de contaminación abyecta por excelencia. Tal como los colonos, el entorno laboral de ellas manifiesta su exterioridad social: las chicherías se ubican en Huanupata, cuyo nombre proviene del "guano". Spira nota que la traducción equivocada de Huanupata de la élite - "morro del basural" (Arguedas, Ríos profundos 207) - subraya la diferencia entre la perspectiva indigenista de Ernesto y la perspectiva hegemónica: "The Spanish reflects the view of Abancay's elite: the neighborhood is a trash heap, a place where you dump that which has no value. To mestizo and Indian populations, however, it is Huanupata, a site of cultural fertility" (Spira 84). Las observaciones de Spira subrayan la presencia del persistente desencuentro epistemológico-ontológico en el texto. Para la clase dominante, las chicherías son asquerosas: "oleadas de moscas volaban en las puertas de las chicherías. En el suelo, sobre los desperdicios que arrojaban del interior, 
caminaba una gruesa manta de moscas. ... Todo era negro de suciedad y de humo" (Arguedas, Ríos profundos 208). Tal como las nubes de insectos alrededor de las chozas de los colonos, las moscas infestan la chichería como si fuera una pila de estiércol.

A diferencia de los colonos, sin embargo, las chicheras no exhiben timidez ni impotencia. Por ejemplo, la sal es reservada para los animales de los terratenientes. Al percibir la escasez de sal para la gente de Huanupata y Patibamba, una situación que ellas consideran injusta, las chicheras montan una rebelión en vez de tolerar el abuso. Salen en motín y públicamente acusan a "los pillos de la Recaudadora" (Arguedas, Ríos profundos 27I) de haber robado la sal. Doña Felipa, la líder de la rebelión, justifica el motín al Padre Linares cuando ese la reprende:

—No, hija. No ofendas a Dios. Las autoridades no tienen la culpa. Yo te digo en nombre de Dios.

- ¿Y quién ha vendido la sal para las vacas de las haciendas? ¿Las vacas son antes que la gente, Padrecito Linares? ...

— ¡No me retes, hija! ¡Obedece a Dios!

—Dios castiga a los ladrones, Padrecito Linares. - dijo a voces la chichera, y se inclinó ante el Padre. El Padre dijo algo y la mujer lanzó un grito:

— ¡Maldita no, padrecito! ¡Maldición a los ladrones! (273)

Felipa recurre tanto a una defensa humanística como a la doctrina bíblica para justificar las acciones de las mujeres. Las chicheras marchan a los colonos de Patibamba gritando “¡Patibambapak!" (para Patibamba) en quechua (279). En contraste con los indígenas que no reivindican un lugar propio en la sociedad hegemónica, las chicheras desafían el trato desigual que les imponen los del interior. Insisten en su humanidad, y la de los colonos, y se reconocen como iguales de los dominantes. Es más, reclaman sus derechos en vez de guardar silencio y aguantar la injusticia. Más reveladora que nada es la manera en que doña Felipa subvierte el lenguaje mismo. Ella emplea la palabra manan, pero de manera autoritaria. Inculca el término con vigor y poder al exigir - en quechua - que el robo de la sal nunca ocurra de nuevo (272). A pesar de que los apoderados las estimen exteriores a la sociedad, ellas rechazan esta subvaloración y actúan para cambiar el sistema social. Para Rancière, esta acción de demandar la igualdad para los que no cuentan en el reparto de lo sensible constituye un acto político (II). Considerado bajo el papel alegórico de la escatología, el motín representa la penetración y profanación del limpio interior corporal por los abyectos excrementos humanos. Esta penetración expone la fragilidad y porosidad de la frontera entre el interior y el exterior. 
La acción de las chicheras produce consecuencias drásticas y la reacción de los apoderados es inmediata y severa. El Coronel llega con tropas para castigar a las chicheras y volverlas a su posición anterior en la sociedad. El castigo impuesto es un llamativo vínculo a la persistente unión de lo escatológico y los socialmente excluidos. Los militares arrestan a las mujeres rebeldes y "las fuetean en el trasero, delante de sus maridos. Como no tienen calzón les ven todo ... Les han metido excremento en la boca" (Arguedas, Ríos profundos 336). La transgresión de las chicheras consta de comportarse como seres políticos que forman parte del interior de la sociedad. Ellas exigen derechos que no les pertenecen y demandan una igualdad que no se aplica a ellas. Como respuesta, los autoritarios buscan restaurar el orden social y volverlas a su posición social asignada. Primero, exponen sus partes femeninas para recordarles, tanto a ellas como al público que las observa, la diferencia que las separa de la hegemonía masculina. De modo parecido las castigan enfrente de sus maridos, intentando recuperar así el establecido orden social. Es más, azotan al cuerpo femenino justo en el sitio que expele lo abyecto. Por último, el Coronel hace que traguen el material abyecto - metáfora de la mujer rebelde que penetra donde no tiene derecho - haciéndolas ingerir el excremento humano que las representa.

Tras el motín los militares buscan controlar a las chicheras rebeldes, y la violencia física representa una forma de dominarlas. De acuerdo con la teoría de la victimización de Badiou, Ariel Dorfman observa:

A lo largo de la novela, hacer llorar es equivalente a atemorizar y empequeñecer. Llorar es lo que hacen los colonos y pongos tratados como indios ... Llorar es lo que desea el Padre Director para indios y niños, lo que la Catedral del Cusco infiltra en los corazones. Hacer llorar a una mujer es, por ende, un modo de afirmarla en su rol de objeto pasivo, de ser marginal, subordinado, mero instrumento de placer o prestigio para el hombre. (III)

Pero las mujeres chicheras no lloran. Rechazan por completo la interpelación como víctimas. En cambio, ellas intercambian insultos con los militares, gritándole "al Coronel, en quechua y en castellano" (Arguedas, Ríos profundos 336). Las chicheras no solo reclaman con habla política, sino que lo hacen tanto en español como en quechua, así reclamando igual legitimidad para ambas lenguas. Aun más llamativa es la respuesta frente al forzado tragar de los excrementos. Una amotinada grita: " $\mathrm{iAl}$ Coronelcito no me lo hagan tragar, pues! ¡Es mierda! ¡Es mierda! ¡Había sido mierda! ¿Han traído mierda desde Cuzco? ¿Qué hechor le ha sacado su porquería? ¡Viva el hecho! ¡Le hará parir al Coronel, por Diosito!” (336-37). Ella desafía la autoridad del "Coronelcito" y de "Diosito" y el mismo diminutivo sirve de 
insulto. Además, se burla de la presunta excepcionalidad masculina por asociar el acto de defecar con el de parir. Y muy de acuerdo con la teoría de lo abyecto de Kristeva y Butler, la chichera recuerda a sus verdugos que aun el oficial más alto defeca, así exponiendo la vulnerabilidad a lo sucio que experimentan todos seres humanos a pesar del estatus social.

Doña Felipa logra penetrar el interior al hacerse oír por los que ejercen la hegemonía, pero es una penetración no autorizada, así que los del interior del cuerpo social se apuran a minimizar los daños y recuperar el control. Otro suceso que revela la dificultad de penetrar al interior del cuerpo político es el conflicto entre el Hermano Miguel, el único clérigo afroperuano que reside y trabaja en el Colegio de Abancay, y Lleras, un estudiante detestable en el Colegio. Lleras reacciona violentamente cuando el Hermano Miguel le marca una falta durante un juego de fútbol. Lleras empuja al Hermano al suelo, gritándole “¡Negro, negro e’ mierda!” (Arguedas, Ríos profundos 3II). En respuesta, Miguel le rompe la nariz y hace que camine de rodillas hasta que le sangran. Recién llegado de dar la misa en las haciendas, el Padre Linares entra en medio de la confrontación y pone fin al castigo. Mientras el Padre Linares sale con los antagonistas para resolver la situación, los otros estudiantes se discuten sobre quién tiene la culpa y qué pasará con los agresores. A pesar de que todos están de acuerdo con que Lleras no debería haber empujado a un clérigo, les escandaliza el hecho de que un hombre negro haya violentado a un chico blanco: "Pero se excedió el Hermano. Que es negro, es negro - dijo en voz alta Valle" (3II, énfasis añadido).

El Padre Linares está de acuerdo con Valle - se excedió el Hermano Miguel. Éste insiste en haber estado en lo correcto: lleva "un hábito de Dios" y ha castigado a Lleras "con la mano de Dios" (Arguedas, Ríos profundos 310II), pero Linares manda que salga de Abancay de inmediato. El Hermano Miguel representa los restos del sistema (no tan) antiguo de la esclavitud en el Perú y la "incorporación" de los negros al interior de la sociedad se revela un proceso reacio e incompleto. La definición de excederse es "Propasarse, ir más allá de lo lícito o razonable", con la frase ejemplar siendo "excederse alguien a sí mismo" ("Excederse"). El Hermano Miguel ha actuado como una parte contada del reparto de lo sensible - pero se equivocó, se excedió. Es más, la reacción de Lleras después de levantarse del suelo - "iEs un negro maldecido!" (3II) - es llamativa al compararse con la teoría de Rancière. En sentido figurado, ser "maldecido" vincula a Miguel con el hablar mal, hacerse sensible mal - es un negro maldecido. ${ }^{18}$ Su papel en la sociedad no es igual al de los blancos, lo que queda evidente cuando Miguel no acata los límites permitidos y es expulsado el mismo día con el fin de recuperar el orden y equilibrio. Antes de salir, el Hermano se dirige a los estudiantes. Les dice: 
Cerca de mi ciudad natal, de San Juan de Mala ... hay un farallón, quiero decir unas rocas altísimas donde el mar golpea. En lo alto de esas rocas se ha descubierto la figura de una Virgen con su Niño. ¿Saben, hijos?, la roca es prieta, más que yo ... Vayan a jugar; con mis humildes manos yo les doy la bendición de esa Virgen; que ella les haga olvidar los pecados que han visto. (Arguedas, Ríos profundos $323^{-24}$ )

El Hermano Miguel se compara con la prieta roca que apoya la estatua de la Virgen, uno de los santos patronos principales en que se funda la Iglesia católica. Reconoce su lugar bajo esas figuras ostensiblemente superiores. Sin embargo, el mensaje por detrás de la disculpa apunta hacia el papel que los afroperuanos han tenido en el desarrollo y la economía del Perú. La esclavitud fue abolida en I854 en el Perú, y, de manera semejante al papel de los colonos en la economía patriarcal-feudal, los esclavos afroperuanos formaron la base laboral explotada sobre la cual el país modernizó. Al escuchar el discurso y la humildad del Hermano, Ernesto se pregunta: “¿Cómo, siendo negro, el Hermano pronunciaba con tanta perfección las palabras? ¿Siendo negro?” (324). Otra vez, el Hermano Miguel habla mal; habla de manera superior al estatus que la sociedad peruana de aquel entonces le ha asignado. A la vez que la frontera sociopolítica se controla por la expulsión de Miguel, la misma frontera resulta vulnerable.

A pesar de todos los esfuerzos por la clase dominante de controlar la frontera discreta que separa a las élites de los marginados en Abancay, surge una situación que hace que la tenue separación social se desate por completo. Una peste, llevada a Abancay desde los colonos de Ninabamba por la Opa Marcelina, infecta la región. Los oficiales pretenden proteger el interior de Abancay por bloquear el puente sobre el río Pachachaca (454). Al cerrar el puente, los oficiales de Abancay intentan exactamente lo que Butler declara insostenible: "For inner and outer worlds to remain utterly distinct, the entire surface of the body would have to achieve an impossible impermeability. This sealing of its surface would constitute the seamless boundary of the subject; but this enclosure would invariably be exploded by precisely that excremental filth that it fears" (170). ${ }^{19}$ El efecto es devastador para la anhelada separación del exterior: por miedo de la peste y frente la posibilidad de morirse pronto, los colonos construyen diez oroyas (puente colgante) para cruzar el río y penetran al interior de Abancay en masa.

Irónicamente, es la religión - la herramienta principal que Padre Linares emplea para controlar a los colonos - que provoca la última y más ruinosa penetración al interior del cuerpo sociopolítico. Con la llegada de la peste, todos los sermones del Padre, los que buscaban provocar miedo del infierno y fe en el poder de Dios, consiguen su propósito: la fe de los colonos les impulsa a dejar atrás el papel de víctima tímida a fin de asegurarse un lugar en el cielo. A fin de cuentas, es su miedo ante la escatología, esta vez 
siendo la escatología mesiánica, o sea "el conjunto de creencias y doctrinas referentes a la vida ultratumba" ("Escatología"), que los impulsa a penetrar al interior prohibido del Perú dominante. Tras cruzar el río Pachachaca, los colonos no entran en Abancay en pánico. Andan tranquilamente rezando y cantando. Su fe en Dios les infunde con sosiego y determinación y parecen más a las chicheras rebeldes que a los colonos tímidos que una vez se escondieron en sus chozas.

Tal como el manan de Doña Felipa y el discurso del Hermano Miguel, el canto de los colonos constituye una acción política según la teoría de Rancière: "Political activity is whatever shifts a body from the place assigned to it or changes a place's designation. It makes visible what had no business being seen, and makes heard a discourse where once there was only place for noise" (30). De tal manera, en Los ríos profundos, el cuerpo expulsado se hace visible con la apropiación de las mismas herramientas que se han empleado en su contra. Las mujeres chicheras demandan - en quechua reconocimiento como seres humanos que merecen los mismos suministros (la sal) y derechos económicos de los terratenientes. El Hermano Miguel se excede con el fin de defenderse y afirmar su mérito como un hombre de Dios. Y los colonos - los que una y otra vez niegan su propio lugar en la sociedad con un sumiso manan - se levantan, no en armas, sino en canción, al enfrentarse con la muerte.

La vulnerabilidad de la frontera porosa construida por la hegemonía peruana expone la naturaleza sintética y contingente de la división entre los poderosos y los marginados. Los ríos profundos incorpora lo escatológico para hacer palpables las estrategias que se han utilizado para marginalizar a varios grupos en el Perú. La escatología también evoca el papel fundamental que los excrementos han tenido en la economía y la historia peruanas, tanto literalmente - el guano fue el producto de exportación principal para el Perú a lo largo del siglo XIX - como figuradamente - en el sentido alegórico que subraya cómo los "excrementos humanos", los que no "cuentan" en la sociedad peruana, son la base laboral de la economía nacional. A la vez demuestra la potencia de una ruptura política que posibilite una reconfiguración del reparto de lo sensible en que el subyugado manan" de los expulsados se cambie a un fuerte manan desafiante ante sus represores.

University of British Columbia 
NOTAS

I Proveo una paginación para cada palabra citada: "mierda" (Arguedas, Ríos profundos 336-37), "excrementos humanos" (283), "excusados" (217), "porquería” (194), "k'echas" (242: "diarrea”), "meones” (242), "k’anra” (225: "asquerosos"). Cito las palabras tal y como Arguedas las escribe. Sin embargo, debe notarse que, en la ortografía moderna quechua, "k'echa" se deletrea "q'icha” y "k'anra" se deletrea "q'anra” (Smith, Soto Ruiz).

2 Para informarse sobre los aspectos autobiográficos, véase "Piedra de sangre hirviendo", de Escribir en el aire (2003) de Antonio Cornejo Polar.

3 Arguedas escribe "el Cusco" con "z", así que, en las citas textuales de Los ríos profundos, se emplea esta ortografía alternativa (el Cuzco). En el resto del ensayo, sin embargo, mantengo la ortografía aceptada (el Cusco).

4 Arguedas define el huayno como "canción y baile popular de origen incaico" (Ríos profundos $\mathrm{I} 74)$.

5 Para saber más sobre el "nuevo indigenismo" en contraste con el "indianismo" y el "indigenismo", véase el "Prólogo" de El mundo es ancho y ajeno (194I) de Ciro Alegría, escrito por Antonio Cornejo Polar, y “'Los ilegítimos' de Pérez Huarancca y la legitimidad del Neo-Indigenismo" de Silvia M. Nagy.

6 Véase "El indigenismo y las literaturas heterogéneas" (1978) de Antonio Cornejo Polar, en que el autor aborda los elementos de la heterogeneidad en la novela, en contraste con "Los ríos profundos: Ópera de pobres" (1983) de Ángel Rama, en que se busca evidenciar la transculturación en la novela.

7 Anthony J. Vetrano, Jean Franco y Ross Larson notan que la obra novelística de Icaza recurre a lo escatológico y lo abyecto para tematizar la injusta degradación que padecen los indígenas tras ser expulsados de su tierra comunera a mano de los hacendados. Icaza mismo afirma que Huasipungo (1953), novela en que sobresale la abyección para subrayar el estado miserable de los colonos, sirve "de mensaje y emoción a las gentes de mi pueblo para la resolución de sus problemas" (2IO, citado en Larson). Por otro lado, la abyección en la obra de Scorza es una especie de venganza literaria. Véase "La metamorfosis en dos personajes de La guerra silenciosa de Manuel Scorza" de Jorge Yviricu para una discusión sobre el papel vindicativo del erotismo escatológico en la obra de Scorza.

8 Véase "The End of Magical Realism" de Alberto Moreiras para una interpretación cautivadora sobre las implicaciones del suicidio de Arguedas para la última novela de éste y para el género literario del realismo mágico.

9 Sergio Franco plantea que, además del mensaje subversivo y carnavalesco (el mundo al revés), el sueño del pongo constituye una confrontación entre la repulsión y el deseo. Para Franco, el juicio final del San Francisco, con su carácter innegablemente erótico y homosexual, subvierte el sistema colonial 
que ha provocado la glotofagia, o "un proceso en el cual la lengua de los dominadores intentó 'devorar' a la de los dominados" (328), del quechua. El pongo toma la palabra para subvertir las estructuras de poder (336). El acto de tomar la palabra forma parte integral de la reivindicación de los grupos marginados en Los ríos profundos.

IO Álvaro García Linera escribe del desencuentro del Marxismo y el Indianismo en Bolivia. Para otros usos del término en la crítica latinoamericana, véanse Julio Ramos, Desencuentros de la modernidad en América Latina (2003) y Freud and Marx in Latin America (2012) de Bruno Bosteels. Sara Castro-Klarén utiliza el término en "Crimen y castigo" (1983), pero su uso trata de los actos sexuales en la narrativa de Arguedas que generalmente "implican un choque entre dos seres marcados por la disparidad más intensa y obvia" (57).

II Lo abyecto, para Kristeva, es "the jettisoned object ... It lies outside, beyond the set, and does not seem to agree to the latter's rules of the game. And yet, from its place of banishment, the abject does not cease challenging its master ... On the edge of non-existence and hallucination, of a reality that, if I acknowledge it, annihilates me. There, abject and abjection are my safeguards. The primers of my culture" (2). Un aspecto importante para el presente estudio es que lo abyecto es parte, pero una parte expulsada, del sujeto.

I2 Apunta Ricardo González Vigil que el bastón con punto de oro es reconocido símbolo de poder en la cultura andina (13).

I3 Arguedas escribe mánan, con tilde, pero en la ortografía moderna, la palabra mana (y la variación manan), que significa "no", se escribe sin tilde. Observo la ortografía moderna aparte de las citas textuales.

I4 Ortega explica: "El uso del habla le está vedado como comunicación distintiva. La estratificación social impone una distorsión del acto mismo de comunicar, estableciendo entre los hombres un ejercicio diferenciado del habla: la sanción de unos, la manipulación de otros" (52).

I5 Le agradezco la interpretación acrisolada del significado de manan a Amanda M. Smith. Me aclaró que la "n" final de manan es un sufijo afirmativo atestiguativo (-n/-mi) elegido por el hablante para agregar énfasis a la palabra que lo acompaña (en este caso "mana"), atestiguando lo que dice la palabra por experiencia propia. En otras palabras, denota agencia y voluntad. De acuerdo con la interpretación de Ortega, es evidente que el pongo emplea manan como renuncia sociolingüística (por elaborar que es "de la hacienda" (157)). Sin embargo, las conclusiones de Ernesto frente al “iMánan!” enfático de los indígenas de Abancay (Arguedas, Ríos profundos 200) exhiben que él también es vulnerable a la epistemología hegemónica que quita agencia de los indígenas.

I6 "And why man is a political animal in a greater measure than any bee or any gregarious animal is clear. For nature, as we declare, does nothing without 
purpose; and man alone of the animals possesses speech. The mere voice, it is true, can indicate pain and pleasure, and therefore is possessed by the other animals as well (for their nature has been developed so far as to have sensations of what is painful and pleasant and to indicate those sensations to one another), but speech is designed to indicate the advantageous and the harmful, and therefore also the right and the wrong; for it is the special property of man in distinction from the other animals that he alone has perception of good and bad and right and wrong and the other moral qualities, and it is partnership in these things that makes a household and a city-state"

(Aristotle i253a).

I7 "Opa" es un término despectivo que quiere decir "tonto, necio, bobo" en quechua (González Vigil 224). "El forastero” (1987), un cuento de Arguedas, trata de otra figura "opa”, María, una guatemalteca que también es maltratada por su estado sucio y su retraso mental. Tal como Ernesto, quien, a diferencia de los otros alumnos del Colegio, le tiene aprecio a la Opa Marcelina, el epónimo forastero del cuento respeta a María y la defiende frente a hombres que intentan abusarla e insultarla. También tiene relaciones sexuales con ella, complicando así el "respeto" que le tiene.

I8 Recordemos que, de modo parecido, el Padre Linares llama "maldita" a Doña Felipa cuando ella le riñe por no darles sal a los pobres, lo que ella rechaza con “¡Maldita no, padrecito! ¡Maldición a los ladrones!” (Arguedas, Ríos profundos 273).

I9 Esta noción de "sealing off" ofrece una vía productiva para comprender el grado y la cantidad de la abyección y lo escatológico en El Sexto (comentado en "Contexto"). A diferencia de Los ríos profundos, lo escatológico en esa novela es vil y pervertido. No hay una perspectiva indigenista que aprecie lo excremental por su valor orgánico, pero tampoco hay mucho que apreciar. Puede que esta distinción tenga que ver con el mismo escenario del texto - la prisión epónima, El Sexto, en Lima - y el hecho de que los prisioneros están completamente aislados del mundo exterior.

\section{OBRAS CITADAS}

ARCH IBALD, PRiscilla. Imagining Modernity in the Andes. Lanham: Bucknell UP, 2 OII.

A RGUEDAS, JosÉ MARí A. "El forastero." Relatos completos. Lima: Editorial Horizonte, 1987 . I9 $\mathrm{I}^{-} 97$.

—. Los ríos profundos. I958. Ed. Ricardo González Vigil, 2ª ed. Madrid: Cátedra, 1998.

-. El Sexto. Barcelona: Editorial Laia, 196r.

—. "El sueño del pongo (cuento quechua)." Relatos completos. Lima: Editorial

Horizonte, $1987.229-37$. 
—. Yawar fiesta. 194I. Lima: Ediciones Nuevo Mundo, 1976.

—. El zorro de arriba y el zorro de abajo. I97I. Buenos Aires: Editorial Losada, I973. A R I T T O L E. "Book I." Politics. Trans. H. Rackham. Perseus Digital Library. Web. B A DIOU, A la In. Ethics: An Essay on the Understanding of Evil. Trans. Peter

Hallward. Brooklyn: Verso, 200 I.

в o st e els, в R un o. Marx and Freud in Latin America: Politics, Psychoanalysis, and Religion in Times of Terror. Brooklyn: Verso, 2012.

B U t LER, J d Dith. Gender Trouble. 1990. New York: Routledge, I999.

CASt R O-Kla Rén, s Ar A. "Crimen y castigo: Sexualidad en J.M. Arguedas." Revista iberoamericana 49.122 (1983): 55-65.

CORNEJO POLAR, ANTONIO. Escribir en el aire: Ensayo sobre la heterogeneidad sociocultural en las literaturas andinas. $2^{\mathrm{a}}$ ed. Lima: Latinoamericana Editores, 2003.

—. "El indigenismo y las literaturas heterogéneas: Su doble estatuto socio-cultural." Revista de Crítica Literaria Latinoamericana 4.7-8 (1978): 7-21.

—, E D. "Prólogo." El mundo es ancho y ajeno, by Ciro Alegría, I94I. Caracas: Biblioteca Ayacucho, 1978.

DO RFMAN, ARIEL. "Puentes y padres en el infierno: Los ríos profundos." Revista de Crítica Literaria Latinoamericana 6.12 (1980): 91-137.

“Escatología." Def. I. Real Academia Española: Diccionario de la lengua española, $23^{\mathrm{a}}$ ed. 2019. Dle.rae.es. Web. 15 enero 2020.

"Escatológico." Def. 2. Fundéu BBVA, 21 diciembre 2008. Fundeu.es. Web. 15 enero 2020.

"Excederse." Def. 2. Real Academia Española: Diccionario de la lengua española, $23^{\mathrm{a}}$ ed. 2019. Dle.rae.es. Web. 15 enero 2020.

FASS EMERY, AMY. "The Eye of the Anthropologist: Vision and Mastery in José María Arguedas." The Anthropological Imagination in Latin American Literature. Columbia: U of Missouri P, 1996. 43-69.

F R A n C 0, JEA N. "The Indianist Novel." An Introduction to Spanish-American Literature. $3^{\text {a }}$ ed. Cambridge: Cambridge UP, 1969. $242^{-5} 55$.

FRANCO, SERGIO R. "Entre la abyección y el deseo: para una relectura de El sueño del pongo." Espéculo: Revista de estudios literarios $\mathrm{I} 2.36$ (2007): 323-4I.

FRE UD, SI G M U N D. "Remembering, Repeating and Working-Through." The Standard Edition of the Complete Psychological Works of Sigmund Freud. Vol. I2. Ed. James Strachey. Trans. Joan Riviere. London: Vintage, 200I. I45-56.

GARCía linera, Álvaro. "El desencuentro de dos razones revolucionarias. Indianismo y Marxismo." Barataria I.3 (2005): 4-I4.

GONZÁ LE Z VIGIL, RiCARD 0, E D. Los ríos profundos, by José María Arguedas, 1958. $2^{\text {a }}$ ed. Madrid: Cátedra, I998.

GOULD , JEFFREY L. "Ignacio Ellacuría and the Salvadorean Revolution." Journal of Latin American Studies 47 (2015): 285-315.

I CAZA, J O R G E. Huasipungo. 1934. Ed. Teodosio Fernández. Madrid: Cátedra, I994. 
K Ris teVA, J U liA. Powers of Horror: An Essay on Abjection. Trans. Leon S. Roudiez. New York: Columbia UP, i982.

LARSO N, Ross. "La evolución textual de Huasipungo de Jorge Icaza." Revista iberoamericana 31.60 (1965): 209-22.

Ló Pe Z-CA lvo, i gn A c i o. “José María Arguedas's El Sexto and the Grotesque Body: The Japanese Character at the Boundaries Of National Belonging." Chasqui: Revista de literatura latinoamericana 41.2 (2012): 137-46.

MAR IÁ T E G I, Jo SÉ CAR Los. Siete ensayos de interpretación de la realidad peruana. Lima: Amauta, 1943.

moreiras, A b B R to. “The End of Magical Realism: José María Arguedas's Passionate Signifier (El zorro de arriba y el zorro de abajo)." The Journal of Narrative Technique 27.I (Winter 1997): 84-II2.

NAGY, Silvia m. “'Los ilegítimos' de Pérez Huarancca y la legitimidad del NeoIndigenismo." Chasqui: Revista de literatura latinoamericana 24.2 (I995): 32-45. o R T E G A, J L L IO. Texto, comunicación y cultura: Los ríos profundos de José María Arguedas. Lima: Centro de Estudios para el Desarrollo y la Participación, 1982.

RAMA, Á NGEL. "Los ríos profundos: Ópera de pobres." Revista iberoamericana 49.122 (I983): $\mathrm{II}^{-} 4 \mathrm{I}$.

R A m os, J u l o. Desencuentros de la modernidad en América Latina: Literatura y política en el siglo XIX. Santiago de Chile: Editorial Cuarto Propio, 2003.

RAN C IÈ E, JA C Ques. Disagreement: Politics and Philosophy. Trans. Julie Rose. Minneapolis: U of Minnesota P, 1999.

Reinhalter burner, LiSA. Fertilizer Dreams: Peruvian and Chilean Culture of the Guano and Nitrate Eras. Ph.D. Dissertation, $\mathrm{U}$ of Illinois at Urbana-Champaign, 2015 .

SANDOVAL, Ciro A., ANd SAndRa M. Boschetto-SAndoval. "José María

Arguedas's El Sexto: The Gestation of an Andean Paradigm of Cultural Revindication." José María Arguedas: Reconsiderations for Latin American Cultural Studies. Eds. Ciro A. Sandoval and Sandra M. Boschetto-Sandoval. Athens: Ohio UP, I998. 138-I66.

SMITH, AMANDA M. Comunicación personal, correo electrónico. 24 agosto 2018. Soto Ruíz, Clodo aldo. Diccionario funcional quechua-castellano-inglés. Vol. I. Lima: CSR-PARWA, S. f.

SPIRA, KAREN. "Toward an Aesthetics of the Abject: Reimagining the Sensory Body in Arguedas's Los ríos profundos." Revista Hispánica Moderna 67.I (2014): 73-89. vetrano, anthony J. "Imagery in Two of Jorge Icaza's Novels: Huasipungo and Huairapamushcas.” Revista de Estudios Hispánicos 6.2 (1972): 293-30I.

YVIRICU, JORGE. "La metamorfosis en dos personajes de La guerra silenciosa de Manuel Scorza." Revista de Crítica Literaria Latinoamericana I7.34 (I99I): 24959. 